\title{
Celebrity Contagion and the Value of Objects
}

\author{
GEORGE E. NEWMAN \\ GIL DIESENDRUCK \\ PAUL BLOOM
}

\begin{abstract}
Why do people purchase objects that were once owned by celebrities, such as film stars or politicians, and also by despised individuals, such as serial killers and notorious dictators? The present studies examine three potential explanations: mere associations, market demands, and contagion (the belief that these objects contain some remnants of their previous owners). Results indicate that while market demands do play a role, contagion appears to be the critical factor affecting the valuation of celebrity possessions. Manipulating the degree of physical contact that a celebrity has with an object dramatically influences consumers' willingness to purchase it, and individual differences in sensitivity to contagion moderate this effect. Additionally, the valuation of celebrity possessions is principally explained by measures of contagion, and subliminally activating the concept of contagion changes consumers' willingness to purchase celebrity objects. Theoretical and practical implications of these findings are discussed.
\end{abstract}

$\mathrm{I}^{\mathrm{n}}$ n 1996, Sotheby's auctioned roughly 1,300 items from the estate of the late Jacqueline Kennedy Onassis. Before the auction began, Sotheby's optimistically estimated the value of the entire lot at around $\$ 4.6$ million. The total yield after 4 days was a staggering $\$ 34.5$ million (USA Today, April 24, 1996). Some notable items included iconic pieces such as President Kennedy's rocking chair, which sold for $\$ 453,500$; his set of golf clubs $(\$ 772,500)$; and the desk on which the president signed the 1963 Nuclear Test Ban Treaty (\$1.43 million). Many of the items, however, had little historical relevance, yet they still fetched remarkable sums of money, such as a tape measure $(\$ 48,875)$ and a set of books on Cape Cod $(\$ 21,850)$. Clearly, these items generated large prices because of where they had been and whom they had

George E. Newman (george.newman@yale.edu) is postdoctoral research associate, Yale School of Management, New Haven, CT 06520. Gil Diesendruck (gil.diesendruck@gmail.com) is senior lecturer of psychology, Bar-Ilan University, Ramat-Gan, Israel 52900. Paul Bloom (paul.bloom@ yale.edu) is professor of psychology, Yale University, New Haven, CT 06520. The authors acknowledge the helpful input of the editor, associate editor, and reviewers.

Debbie MacInnis served as editor and Darren Dahl served as associate editor for this article.

Electronically published February 8, 2011 come into contact with, not their tangible properties or functional utility. For example, if the buyer of the tape measure discovered that it was actually not from the Kennedy household, he would presumably be outraged and want his $\$ 48,875$ back, though nothing perceptible or tangible about the object would have changed.

The valuation of celebrity items, however, is not restricted to positively regarded figures, such as JFK. Curiously, there is also a market for items once belonging to hated and despised individuals. For example, items such as Charles Manson's hair, paintings by John Wayne Gacy, and the personal effects of Saddam Hussein have been sold at specialty auctions, sometimes fetching tens of thousands of dollars per item (Stone 2007). And, recently, the U.S. government auctioned several items that belonged to the notorious fraudulent investor Bernard Madoff, including a footstool, originally listed at $\$ 360$, which sold for $\$ 3,300$, and a nondescript bar set, originally listed at $\$ 680$, which sold for $\$ 2,200$ (New York Times, November 15, 2010). Why are these objects valued? Do people value objects that belonged to despised individuals for the same reasons they value objects that belonged to well-regarded individuals?

One explanation is that celebrity possessions are valued because of their associations. Objects that were once owned or touched by specific people remind us of those people. This captures the fact that objects associated with admired 
individuals are positively valued. However, it also predicts that objects belonging to individuals who are explicitly disliked should carry no value at all. A second explanation has to do with intuitions about how these objects are valued by others (their market value). For instance, we might value objects that belonged to celebrities because we believe that there are other people who would later purchase them from us at higher prices or because others would be impressed that we own such things. A third account is rooted in the concept of contagion (Belk 1988; Rozin, Millman, and Nemeroff 1986). This is the belief that a person's immaterial qualities or "essence" can be transferred to an object through physical contact.

The present studies demonstrate that the mere association of an object with a well-liked individual does not appear to be a significant driver of value. Moreover, while market forces do play a role, contagion appears to be the critical factor affecting the valuation of celebrity possessions. Specifically, we find that manipulating the degree of physical contact that a celebrity has with an object dramatically influences consumers' willingness to purchase it, and individual differences in sensitivity to contagion moderate this effect. Additionally, the valuation of celebrity possessions is principally explained by measures of contagion, and subliminally activating the concept of contagion changes people's willingness to purchase celebrity objects. In the remainder of this article we review the previous work on contagion and celebrity possessions and report the results of three experiments that use converging methodologies to test the role of contagion in the valuation of celebrity possessions.

\section{MEMORIES, MONEY, AND MAGIC}

Why do people pay money for celebrity possessions? The phenomenon itself is somewhat of a puzzle. Celebrity items often have little functional value; that is, there is no direct functional benefit afforded by an object that belonged to someone famous versus one that did not. Moreover, because the objects themselves tend to be relatively common artifacts (clothing, furniture, etc.), they are often physically indistinguishable from a number of seemingly identical products in the marketplace. Nevertheless, people are willing to pay surprisingly large sums of money to own these objects. This raises the question, if it is not something that can be seen, felt, or in any way directly experienced, what is it that makes celebrity possessions so valuable? In this article we examine three potential explanations.

\section{Associations}

One relatively straightforward explanation is that these objects are valued for their associations. A great deal of research in psychology and consumer behavior has documented people's tendency to keep and collect items that have some degree of sentimental value, even if the objects themselves are relatively worthless (Belk 1988; Grayson and Shulman 2000; O’Guinn 1991; O’Guinn and Belk 1989).
Moreover, in many cultures, celebrities (such as movie stars or politicians) occupy a unique and often highly regarded place in society (Belk 1988, 1995; Cornfeld and Edwards 1983; Douglas and Isherwood 1979; McCracken 1989; O'Guinn 1991; O'Guinn and Belk 1989). Therefore, it may be that people want to own celebrity possessions for the same reasons that they want to collect souvenirs from a memorable vacation or a ticket stub from a particularly enjoyable concert (Zauberman, Ratner, and Kim 2009). Celebrities are well regarded, and people may experience positive emotions when they think about them. In turn, an object that belonged to that celebrity is valued because it serves as a physical reminder that helps people to relive those pleasurable emotional states.

Indeed, past research on this topic has discussed the ways in which memorabilia or "relics" (records, posters, clippings, etc.) may have an important emotional connection to memories and one's sense of self (O'Guinn 1991). Thus, from an associative view, celebrity possessions themselves are not qualitatively different from other types of memorabilia. These objects are valued because they are associated with, and therefore serve as reminders of, highly regarded individuals. However, this explanation also predicts that objects belonging to individuals who are explicitly disliked should carry no value at all, and hence, only the people who admire individuals such as Saddam Hussein or Charles Manson (for whatever reason) should positively value their possessions.

\section{Market Forces}

A second explanation of this phenomenon appeals to far more pragmatic concerns-namely, the potential value of these items to others. Celebrity possessions are often one of a kind, which by definition makes them a scarce commodity. Moreover, there is often a substantial discrepancy between the intrinsic value of celebrity items and their market value. For example, someone recently paid $\$ 160$ for a piece of used bubble gum that was chewed by Brittany Spears. Therefore, it may be that people purchase celebrity possessions primarily because they recognize that these items are scarce and potentially valuable to others.

There is, of course, a sense in which this account is circular. That is, why do other people want these items? And yet, there have been several historical instances in which scarcity itself has driven an enormous and highly lucrative market. For example, at the height of the "Dutch tulip mania" in 1637, a single tulip bulb sold for over 4,000 guilders, while less than a year earlier, tulips sold for a small fraction of that amount (Mackay 1841; Thompson 2007; also see Garber 1989, 2000). Similar explanations have been proposed for more recent phenomena such as the collection of Beanie Babies, which offered an annual rate of return of approximately 170\% from 1994 to 1999 (Burton and Jacobsen 1999). Given the large sums of money paid for celebrity possessions, it is certainly possible that people purchase these items based on the assumption that their market value will continue to increase. Consistent with this notion, Burton and Jacobsen (1999) estimate that the annual rate of 
return on collectibles sold at major auction houses is between $11 \%$ and $14 \%$, and a survey of collectors found that $22 \%$ reported financial investment as a significant motivation for their collecting behavior (Formanek 1991).

\section{Contagion}

A third explanation comes from the concept of contagion. Contagion is commonly thought of as a form of magical thinking in which people believe that a person's immaterial qualities or essence can be transferred to an object through physical contact (Belk 1988; Bloom 2004, 2010; Frazer 1890; Mauss 1902; Nemeroff and Rozin 1994; Rozin et al. 1989; Tylor 1871). Anthropologists first proposed the concept in the late nineteenth century when they observed several cultural practices emphasizing the transfer of a person's identity (or soul) to inanimate objects. The most "contagious" objects were actual physical remnants of the person, such as clippings of hair or fingernails. However, such beliefs seemed to carry over to inanimate objects, particularly objects that had come into physical contact with the person.

The concept of contagion has been examined in a wide range of experimental contexts (Argo, Dahl, and Morales 2006, 2008; Mishra 2009; Morales and Fitzsimons 2007; Nemeroff and Rozin 1994; Rozin et al. 1986). For example, Nemeroff and Rozin (1994) asked participants to sequentially imagine a sweater that came into contact with a range of different individuals, for example, a lover, someone evil, or someone admired. Participants were asked to rate how pleasant or unpleasant they would find the experience of wearing the sweater. Then participants were asked to imagine their willingness to wear the sweater following a range of possible transformations that included different ways of cleaning the sweater (e.g., deodorizing it, boiling it) as well as a number of structural changes (cutting it up, burning it, etc.). In sum, participants reported that while they would be happy to wear a sweater worn by a loved one or someone they admired, they would refuse to try on a sweater worn by someone evil, such as Adolf Hitler (Nemeroff and Rozin 1994; Rozin et al. 1989).

More recently, Argo et al. (2006, 2008) conducted related studies supporting the role of contagion beliefs in consumer contexts. For example, they found that in a retail setting, people were reluctant to purchase a T-shirt if it was just tried on by a stranger (Argo et al. 2006). However, people were more likely to purchase an item if it came into contact with an attractive salesperson of the opposite sex (Argo et al. 2008). In both sets of studies, the authors found that willingness to pay and purchase intentions were linked to the item's physical contact with those presumably negative or positive sources, supporting the notion that both positive and negative attributes may be transmitted through the process of contagion.

Furthermore, qualitative research has discussed the potential role of contagion in the valuation of celebrity items (Belk 1995; O'Guinn 1991; O'Guinn and Belk 1989). For example, O'Guinn (1991) examined the collections of members of the Central Midwest Barry Manilow Fan Club and noted that the most valuable items were "things in the collection that actually touched Barry" (6). Similarly, McCracken (1986) has discussed the process by which owners impart meaning to their objects through ownership and physical contact and the "divestment rituals" that consumers go through when purchasing used objects that are believed to contain remnants of their previous owners (McCracken 1986, 1989). Taken together, this work suggests that contagion may be one explanation for people's willingness to have contact with an object previously owned by a celebrity. However, in light of the competing explanations outlined above (associations and market demands), it is unclear whether contagion alone provides a sufficient explanation for people's desire to purchase such items.

\section{THE CURRENT STUDIES}

The primary goal of this article is to examine the degree to which contagion beliefs account for the valuation of celebrity items. Specifically, we are interested in when contagion beliefs may play a role, how they might interact with the additional factors of associations and market demands, and what types of manipulations are likely to activate or inhibit such beliefs. Such an investigation is important in that it helps to answer practical questions regarding the psychological factors surrounding consumers' desire to purchase celebrity items (as well as perhaps other types of collectibles). At a broader theoretical level, it serves to potentially expand our understanding of the concept of contagion itself by illustrating how notions of contagion may exist alongside competing sources of value, such as market demands.

To examine these issues, the present studies assess consumers' valuation of both positive and negative celebrity possessions. In the first experiment, we employ a relatively straightforward approach by assessing valuation of both celebrity and noncelebrity possessions. We subsequently measure the dimensions of contagion, perceived market value, and associations in order to determine the relative contribution of each of these factors. Experiment 2 uses a different "transformation" paradigm to examine the effects of directly manipulating both "contagion potential" (the degree of physical contact between the celebrity and the object) and market demands (the potential to resell the item to others). In this study, the associative account served as the null hypothesis since associations between the object and the celebrity were preserved across all manipulations. Additionally, in this study we examined individual differences in contagion sensitivity (Haidt, McCauley, and Rozin 1994) with the notion that differences along this dimension might moderate the effects of physical contact. Finally, experiment 3 manipulated sensitivity to contagion via a priming manipulation and subsequently measured consumers' willingness to purchase celebrity possessions.

The present studies use a number of converging approaches to identify the psychological processes underlying the valuation of celebrity possessions. These studies contribute to the existing literature as they are the first to experimentally test and manipulate various reasons for why 
people value celebrity possessions. Additionally, these studies illustrate how contagion may interact with competing sources of value, such as associations and market demands.

\section{EXPERIMENT 1}

In experiment 1 , participants were asked to evaluate a series of objects that belonged to a target individual who varied along two dimensions: his or her valence (positive, negative, mixed) and fame (celebrity vs. noncelebrity). Our primary dependent measure was valuation of the object (one's desire to purchase and own it). However, we also obtained several process measures: an indirect measure of contagion (willingness to touch the person and the object), market value (belief that someone else would want to purchase the item), liking of the person (association), and the perceived historical significance of the item.

\section{Method}

Participants were 245 adults $\left(M_{\text {age }}=35.2,67 \%\right.$ female $)$ who were recruited from an online database maintained by Yale University. Participants were randomly assigned to one of six conditions in a 3 (valence: positive, negative, mixed) $\times 2$ (fame: celebrity, noncelebrity) between-subjects design.

Each participant was first asked to generate the name of an individual. The instructions used to elicit this name varied by condition. For example, participants in the positive celebrity condition read, "In the space below please provide the name of a living celebrity or public figure (not someone you know personally) who you consider to be incredibly moral." In the negative celebrity condition, the word "moral" was replaced with "immoral." In the mixed-valence conditions participants were asked to name a person "who you consider to be of mixed moral valence; i.e., someone who is both moral at times and immoral at other times." Valence of the target individual was manipulated in terms of morality because morality is a dimension that is readily identified as positive or negative and can be shared by celebrities and noncelebrities alike.

In the noncelebrity conditions the wording was identical except that participants were asked to "provide the name of a living person (someone you know personally)." As a manipulation check for fame (celebrity vs. noncelebrity), participants were asked to rate how famous the person was (1 $=$ not at all famous, $9=$ extremely famous).

Participants were then asked to imagine an item that belonged to the individual that they had named (e.g., a wristwatch) and completed a series of items, which measured the primary dependent measure (valuation) and several process measures. Measurement of the item's value included three items: "How much would you like to own this item? How likely would you be to purchase this item if it was for sale? Is this item worth keeping, or would you throw it out?" ( $\alpha$ $=.83$; Frazier et al. 2009). The measure of contagion asked about people's desire to have physical contact with the person as well as with the object itself: "How much would you want to give this person a hug or shake their hand? How much would you want to hold this item in your hands?" ( $\alpha$ $=.72$ ). The measure of perceived market demand included two items: "Are there some people who would pay money for this item? Would other people be impressed if they found out that you owned this item?" $(\alpha=.81)$. Additionally, we asked about liking the individual $(1=$ extreme disliking, $9=$ extreme liking) because an associative account should predict that liking should be positively correlated with valuation. We also asked participants to rate the perceived historical significance of the item: "Does this item have historical value (e.g., should it be in a museum)?" Except for the measures of liking and fame, all responses were made on 9 -point scales, where $1=$ not at all and $9=$ very much so. The order in which each of these items appeared was randomized for each participant.

This entire procedure (generating the name of an individual person and evaluating one of his/her possessions) was repeated three times, such that each participant listed three different individuals. The type of person (e.g., positive celebrity) remained constant throughout. However, each time the task was repeated, participants were asked to evaluate a different type of object. The items included a wristwatch, a sweater, and a pair of gloves, and the order in which these items appeared was fully counterbalanced across participants.

The order in which the items were presented did not affect the results $(F<1)$, so it was dropped from all further analyses. Similarly, the type of object (wristwatch, sweater, pair of gloves) did not affect the results (all $p>.28$ ). Therefore, for each participant we averaged the ratings across the different objects to produce one score for each type of measure (item value, contagion, market value, liking, and historical significance).

\section{Results}

As expected, participants rated the celebrities $(M=7.91)$ as more famous than the noncelebrities $(M=1.38 ; p<$ $.0001)$. However, 28 participants listed famous individuals when they were asked to list noncelebrities. These participants were excluded from the subsequent analyses, which left usable data from a total of 217 participants.

The results from this study are depicted in figure 1. Participants valued items belonging to celebrities $(M=3.79)$ significantly more than items belonging to noncelebrities $(M=3.02 ; F(1,211)=11.42, p<.001)$. Analogously, participants valued objects belonging to the positive targets the most $(M=4.33)$, less so for objects owned by mixedvalence targets $(M=3.68)$, and the least for negative targets $(M=2.19 ; F(2,211)=29.48, p<.001)$. There was no interaction between these factors $(p=.21)$.

For the measures of contagion, there was a significant main effect of valence $(F(2,211)=66.55, p<.001)$ and a significant interaction between valence and fame $(F(2$, $211)=3.12, p<.05)$. When the valence of the target was positive, participants reported wanting to have marginally more contact with the celebrity and the celebrity object 
FIGURE 1

RESULTS FROM EXPERIMENT 1

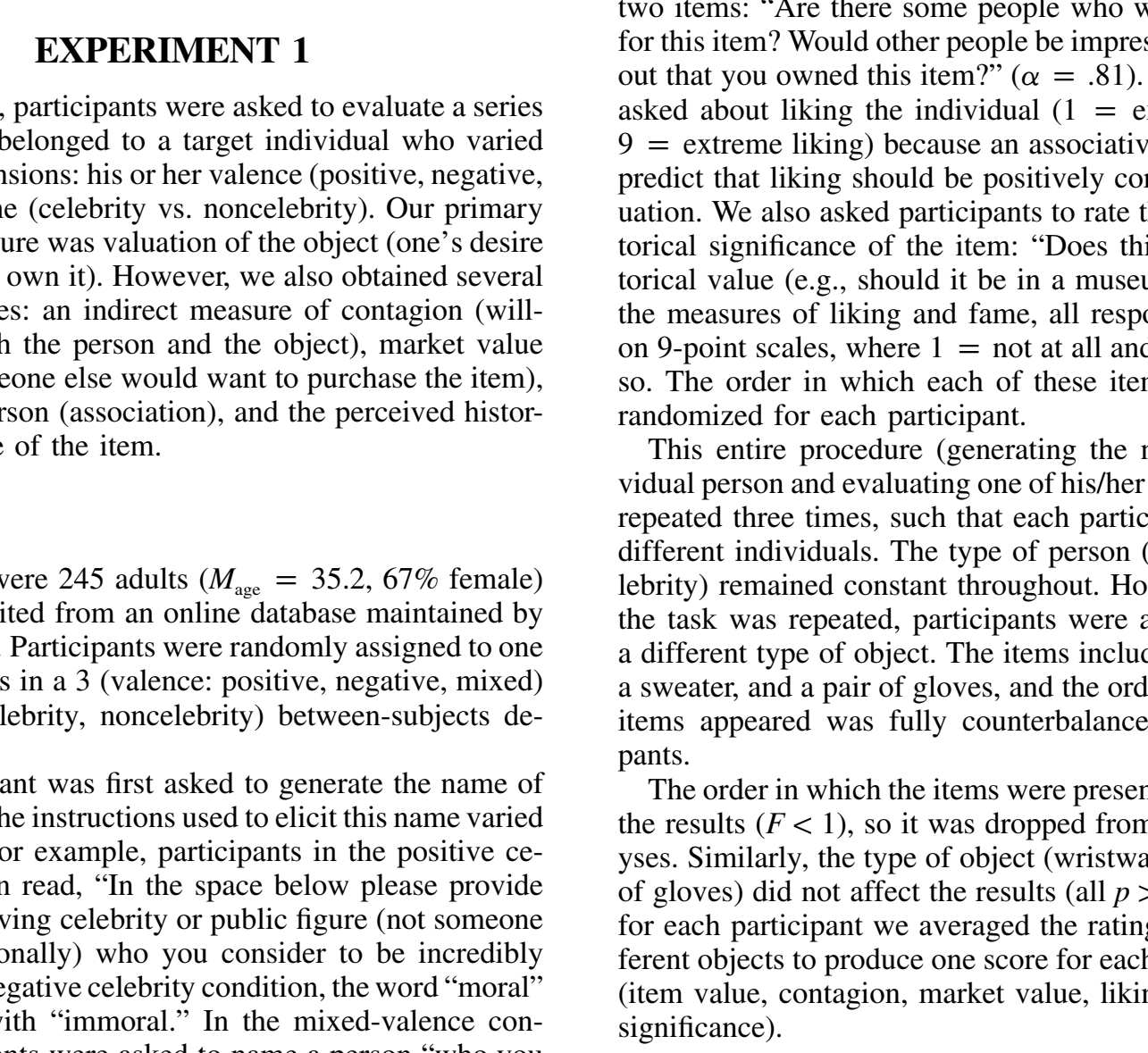

$(M=5.87)$ than with the noncelebrity $(M=5.18 ; F(1$, $65)=2.47, p=.12$ ). However, when the target valence was negative, participants instead reported wanting to have more contact with the noncelebrity $(M=2.50)$ than with the celebrity $(M=1.77 ; F(1,68)=5.45, p<.05)$. The mixed-valence targets followed the same pattern as the negative targets ( $M=4.14$ and 3.81, respectively), though this difference was not statistically significant. These patterns suggest that desire to have contact with (or avoid) contagion items may be "stronger" for celebrities than for noncelebrities.

For perceptions of market value, there was a significant main effect of fame $(F(1,211)=328.06, p<.001)$ as well as a significant interaction between fame and valence $(F(2$, $211)=5.08, p<.01)$. For celebrities, the market value of the item decreased as the celebrity became more negative $(F(1,122)=5.60, p<.01)$. For noncelebrities there was no effect of valence on perceived market value $(p=.39)$. Ratings of historical significance followed a pattern identical to that of market value with both a main effect of fame (celebrity objects were rated as more historically significant) and an interaction between fame and valence $(p<.01)$.

Regression Analyses. We then conducted a hierarchical linear regression analysis to examine the degree to which each of the measures (contagion, market value, liking, and historical significance) predicted measures of valuation. The results of this analysis are reported in table 1 . In sum, measures of contagion appeared to account for the effects of target valence on valuation, while measures of market value appeared to account for the effects of target fame. In contrast, measures of liking were not predictive and measures of historical significance were only marginally related.

To verify the specific mediating relationships between these factors we used bootstrapping analyses that allowed for the examination of multiple mediators (Preacher and Hayes 2008; Shrout and Bolger 2002; Zhao, Lynch, and Chen 2010). We first examined the indirect effects of target valence on item valuation, through the mediators of contagion, market value, liking, and historical significance. Al- 
TABLE 1

HIERARCHICAL REGRESSION RESULTS FROM EXPERIMENT 1

\begin{tabular}{|c|c|c|c|c|c|c|c|c|c|c|}
\hline \multirow[b]{2}{*}{ Outcome } & \multirow[b]{2}{*}{ Predictor } & \multicolumn{2}{|c|}{ Step 1} & \multicolumn{2}{|c|}{ Step 2} & \multicolumn{2}{|c|}{ Step 3} & \multicolumn{2}{|c|}{ Step 4} & \multirow[b]{2}{*}{$\Delta R^{2}$} \\
\hline & & $\beta$ & $t$-value & $\beta$ & $t$-value & $\beta$ & $t$-value & $\beta$ & $t$-value & \\
\hline \multirow[t]{3}{*}{ Contagion } & Fame & -.02 & -.28 & & & & & & & \\
\hline & Valence & .58 & $10.64^{\star \star}$ & & & & & & & \\
\hline & Fame $\times$ valence & .14 & $2.47^{\star}$ & NA & & NA & & NA & & \\
\hline \multirow[t]{3}{*}{ Market value } & Fame & .77 & $18.27^{\star \star}$ & & & & & & & \\
\hline & Valence & .08 & $1.74^{+}$ & & & & & & & \\
\hline & Fame $\times$ valence & .13 & $3.09^{\star}$ & NA & & NA & & NA & & \\
\hline \multirow[t]{7}{*}{ Item value } & Fame & .17 & $2.84^{\star}$ & .18 & $4.58^{\star \star}$ & -.06 & .88 & -.09 & 1.42 & \\
\hline & Valence & .44 & $7.29^{\star \star}$ & -.04 & .80 & -.02 & .43 & -.02 & .27 & \\
\hline & Fame $\times$ valence & .08 & 1.26 & -.04 & .87 & -.07 & $1.67^{+}$ & -.07 & $1.85^{+}$ & \\
\hline & Contagion &. & . . & .83 & $16.37^{\star \star}$ & .76 & $14.94^{\star \star}$ & .74 & $10.76^{\star \star}$ & $.42^{\star \star}$ \\
\hline & Market value & . . & . . &. & . . & .31 & $4.74^{\star \star}$ & .27 & $4.01^{\star *}$ & $.03^{\star \star}$ \\
\hline & Liking (association) & .. & . . & . . & . . & . . & . . & -.01 & .08 & .000 \\
\hline & Historical value & . . & . . & . . & . . & . . &.. & .10 & $1.84^{+}$ & $.005^{+}$ \\
\hline
\end{tabular}

${ }^{+} p<.10$.

${ }^{*} p<.05$.

${ }^{\star *} p<.001$.

though weak, there was a significant indirect effect of valence on valuation through market value $(b=.02, \mathrm{SE}=$ $.01 ; 95 \%$ confidence interval $[\mathrm{CI}]=.001$ to .05$)$, which was driven primarily by celebrities (see fig. 1). More important, however, even when controlling for the effect of market value (as well as historical significance and liking), there was a significant indirect effect of valence through contagion $(b=.44, \mathrm{SE}=.06 ; 95 \% \mathrm{CI}=.32$ to .56$)$. Thus, manipulations of target valence affected contagion (wanting to touch the item or the person), which in turn changed participants' desire to purchase or own the item.

An identical set of analyses examined the effect of fame on valuation. A bootstrapping analysis indicated that there was a significant indirect effect of fame on valuation through perceived market value $(b=.17, \mathrm{SE}=.05 ; 95 \% \mathrm{CI}=$ .08 to .28). However, none of the other mediating variables had a significant indirect effect. Thus, manipulations of target fame affected the perceived market value of the item, which in turn changed participants' desire to purchase or own the item.

\section{Discussion}

The results from the first study are informative for a number of reasons. We observed a significant interaction between celebrity valence and measures of contagion such that people wanted more contact with positive celebrity items (compared to noncelebrity items) but less contact with negative celebrity items. Moreover, the regression/mediation analyses demonstrated that both contagion and market demands (but not general liking of the individual or perceived historical significance) explained participants' valuation of the celebrity items.

Putting these results together, we are able to dissociate the effects of contagion, market demands, and associations. Overall, associations do not appear to play a significant role. Measures of liking/disliking did not predict measures of valuation. However, we did observe significant effects of both contagion and market demands, which appeared to operate differently depending on the valence of the celebrity. Positive celebrity possessions appeared to be valued both for their contact with an admired individual (contagion) and for their market value. In contrast, for negative celebrities, contagion and market demands appeared to play contrasting roles in that perceived market demand increased the value of the object (relative to an item owned by a negative noncelebrity) whereas contagion decreased the value. In the following study we examine this interaction between contagion and celebrity valence more directly.

\section{EXPERIMENT 2}

Experiment 2 employed a converging methodology, originally developed by Nemeroff and Rozin (1994), which asked participants to think of an item that was previously owned by someone famous-either a positive celebrity or a negative celebrity. After providing baseline values for their willingness to purchase the item, participants were exposed to one of four different manipulations: two that manipulated the degree of physical contact with the item (the item's contagion potential) and two that affected the market demand for the item. Depending on condition, the celebrity's contact with the item was either highlighted (stating that the person had a lot of contact with the item) or decreased (stating that even though the object was owned by the celebrity, he/she never actually touched it). Similarly, the perceived market value of the item was either highlighted (stating that there was a great deal of demand for items owned by that person) or decreased (stating that there was little demand for items owned by that person). Crossing these factors produced eight conditions in a $2 \times 2 \times 2$ betweensubjects design.

On the basis of experiment 1, we predicted that for both positive and negative celebrities, highlighting demand for 
the item should increase purchase intentions while decreasing demand should decrease purchase intentions. However, for manipulations of contact (i.e., contagion potential), we predicted an interaction with celebrity valence. Highlighting contact with positive celebrities should increase purchase intentions because of the transfer of positive "essence," while highlighting contact with negative celebrities should decrease purchase intentions because of the transfer of negative "essence." Stated formally, the hypotheses were as follows:

H1a: For both positive and negative celebrities, highlighting perceived demand should increase purchase intentions while decreasing demand should decrease purchase intentions.

H1b: Manipulations of contact should interact with celebrity valence. For positive celebrities, highlighting physical contact should increase purchase intentions while for negative celebrities highlighting physical contact should decrease purchase intentions.

Thus, the interaction between celebrity valence and manipulations of physical contact was the primary test of the contagion mechanism. This study did not manipulate associations directly. Rather, an associative account served as the null hypothesis since in all conditions the association between the object and the celebrity was preserved.

Additionally, we were interested in factors that may moderate the effects of contagion. Previous research has established that individuals may differ in their degree of sensitivity to contagion. For example, differences in contagion sensitivity predict a person's willingness to have contact with negatively contaminated items (Haidt et al. 1994; Rozin, Fallon, and Mandell 1984). In this study, we predicted that contagion sensitivity should moderate the relationship between celebrity valence and purchase intentions. Specifically, higher sensitivity to contagion should be positively related to a desire to purchase objects owned by positive celebrities. However, higher contagion sensitivity should also be negatively related to a desire to purchase objects owned by negative celebrities since in this case worry about negative contamination may trump any desire to own the object for its perceived market value. Moreover, highcontagion sensitivity individuals should be more sensitive to the manipulation of physical contact than low-sensitivity individuals. Thus, we used individual differences in contagion sensitivity as a converging test of the contagion mechanism.

H2a: Higher degrees of contagion sensitivity should be positively related to willingness to purchase objects owned by positive celebrities but negatively related to willingness to purchase objects owned by negative celebrities.

H2b: High-contagion sensitivity individuals should be more sensitive to the manipulation of physical contact than low-sensitivity individuals.

\section{Method}

We recruited a new group of 455 participants $\left(M_{\text {age }}=\right.$ $34.1,64 \%$ female) from the same online panel. Participants were randomly assigned to one of eight between-subjects conditions in a 2 (valence: positive vs. negative) $\times 2$ (manipulation: contagion vs. market value) $\times 2$ (direction: highlighted vs. decrease) between-subjects design.

Participants were first asked to provide the name of either a celebrity whom they deeply admired or a celebrity whom they despised. The instructions (taken from Nemeroff and Rozin [1994]) used to elicit names in the positive celebrity conditions were as follows: "In the space below please provide the name of your favorite living celebrity or public figure. This could be a movie star, a musician, a professional athlete, a politician, etc. This should be someone whom you like very much and admire and would be excited to meet personally." In contrast, participants in the negative condition read, "In the space below please provide the name of a living person, whom you consider to be evil, or to personify evil; not someone you know personally, but a villain. This could be a mass murderer, or a fanatical leader-someone that you have strong negative feelings about." As a manipulation check, participants were also asked to indicate using a binary measure whether or not the person they named was someone they "knew personally" and whether the person was someone "that the average person has heard of."

Next, participants were asked to imagine that they had the opportunity to bid on a sweater that belonged to that individual. Participants were asked to report their willingness to purchase the sweater compared to an identical used sweater (in the same condition) that was not owned by the person they had named $(1=$ much less likely to purchase, $9=$ much more likely to purchase). Participants also rated on a 9-point scale how pleasant they would find the experience of wearing the sweater $(1=$ extremely unpleasant, $9=$ extremely pleasant).

On a subsequent page, participants were then exposed to one of four different manipulations. For each type of manipulation (physical contact or market value) the manipulation either highlighted or decreased that dimension. Thus, the celebrity's physical contact with the item was either highlighted ("This sweater was given to [- $]$ as a gift and it was one of [his/her] favorite sweaters and [he/she] wore it often") or decreased ("This sweater was given to [as a gift, but [he/she] never actually wore it or even opened the box that it came in"). Similarly, the market value of the item was either highlighted ("There is a lot of demand for items owned by [- $]$, so if you wanted to, it is highly likely that you could resell the sweater to someone else") or decreased ("There is very little demand for items owned by [- $]$, so even if you wanted to, it is highly unlikely that you could resell the sweater to someone else"). After reading about one of these four manipulations, participants were again asked to report their intent to purchase the celebrity object as well as the pleasure they would derive from wearing it. Our main dependent measures were the differ- 
FIGURE 2

\section{RESULTS FROM EXPERIMENT 2}

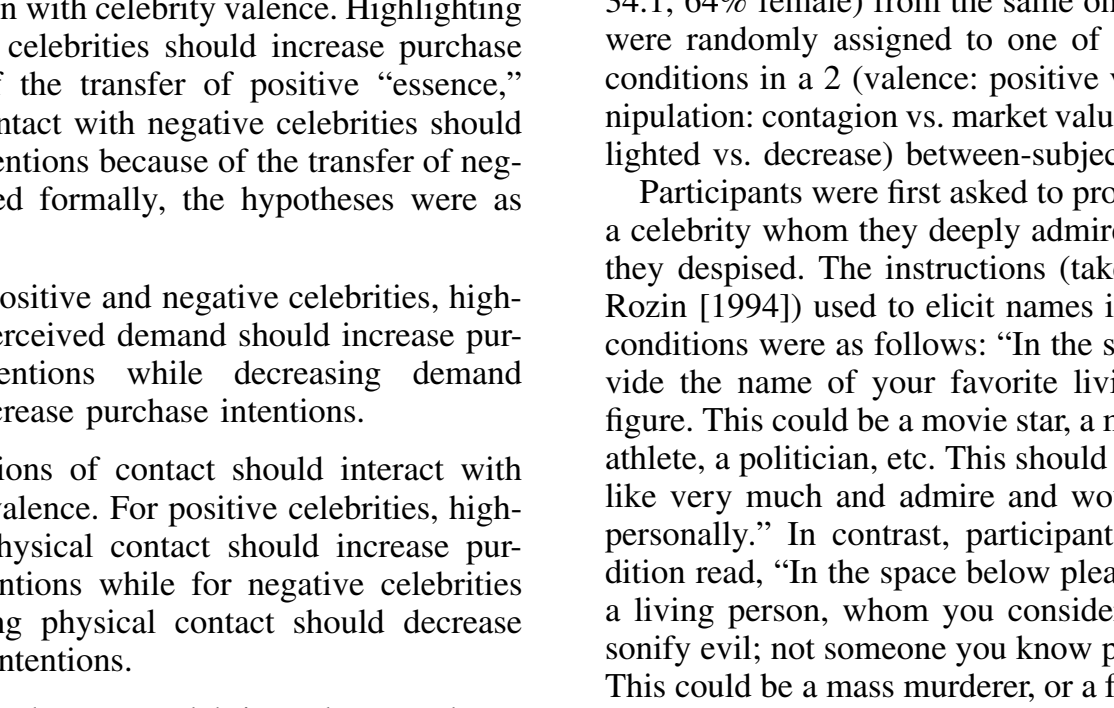

NOTE.-Higher numbers indicate a greater desire to purchase or wear the item. The darker bars represent conditions in which the contact or demand was highlighted, while the lighter bars represent conditions in which contact or demand was decreased.

ences in participants' scores after reading one of the manipulations versus before reading.

\section{Individual Differences in Measures of Contagion Sen-} sitivity. At the end of the study, all participants were asked to respond to three additional items that were adapted from Haidt et al. (1994) and assessed their sensitivity to contagion. These three items included, "Even if I were hungry, I would not drink a bowl of my favorite soup if it had been stirred by a used but thoroughly washed flyswatter. It would bother me to sleep in a nice hotel room if I knew that a man had died of a heart attack in that room the night before. If a friend offered me a piece of novelty chocolate shaped like dog-doo, I would not eat a bite." All responses were made on a 9-point scale, where $1=$ strongly disagree and $9=$ strongly agree. These three measures were all significantly correlated with one another (all $p<.001)$ and loaded onto a single factor.

\section{Results}

Manipulation Check. Nearly all participants (98.6\%) responded that the person they named was not someone whom they knew personally. A greater percentage of the participants in the negative celebrity conditions said that the average person had heard of the celebrity $(94.5 \%)$ compared to the positive celebrity conditions $\left(84.7 \% ; \chi^{2}=11.72, p\right.$ $<.001)$. This difference was driven by variance in the celebrities listed across the two types of conditions. Only 58 different negative celebrities were named, while 171 dif- ferent positive celebrities were named (i.e., nearly every participant in these conditions named a different person). Including only participants who named an individual that "the average person had heard of" did not change the results in any way. Therefore, the analyses were performed using the entire data set. There was no main effect or interaction with participant gender (all $p>.7$ ).

Purchase Intentions. Results from this study are depicted in figure 2. Consistent with a contagion account, we observed a significant interaction between manipulations of physical contact and celebrity valence $(F(1,219)=16.77$, $p<.001)$. For positive celebrities, highlighting the amount of contact increased purchase intentions $\left(M_{\text {diff }}=+.32\right)$ while decreasing contact decreased purchase intentions $\left(M_{\text {diff }}\right.$ $=-1.58 ; F(1,111)=17.43, p<.001)$. However, for negative celebrities the opposite was true: decreasing contact increased purchase intentions $\left(M_{\text {diff }}=+.43\right)$, whereas highlighting contact decreased purchase intentions $\left(M_{\text {diff }}=\right.$ $-.33 ; F(1,108)=2.69, p=.10)$. As expected, manipulations of market value had similar effects on both positive and negative celebrity objects. For positive celebrities, highlighting market demand increased purchase intentions $\left(M_{\text {diff }}\right.$ $=+.74)$ while decreasing demand decreased purchase intentions $\left(M_{\text {diff }}=-.33 ; F(1,118)=8.35, p<.01\right)$. Similarly, for negative celebrities, highlighting demand increased purchase intentions $\left(M_{\text {diff }}=+.89\right)$ while decreasing demand decreased purchase intentions $\left(M_{\text {diff }}=-1.0 ; F(1,108)=\right.$ 21.24, $p<.001)$. 
Pleasure from Wearing. As can be seen in figure 2, for positive celebrities, highlighting contact increased participants' desire to wear the sweater $\left(M_{\text {diff }}=+.02\right)$ while decreasing contact significantly reduced participants' desire to wear the sweater $\left(M_{\text {diff }}=-1.12 ; F(1,111)=12.46, p\right.$ $<$.001). In contrast, for negative celebrities, decreasing contact significantly increased participants' desire to wear the sweater $\left(M_{\text {diff }}=+.71\right)$ while highlighting contact did not change participants' desire to wear the sweater, which remained at the bottom of the scale $\left(M_{\text {diff }}=.04 ; F(1,108)=\right.$ 12.26, $p<.001)$. Manipulations of market value had no effect on ratings of wanting to wear the sweater for either positive or negative celebrities (both $p>.3$ ).

Contagion Sensitivity. We then used regression analyses to test our prediction regarding the moderating effects of contagion sensitivity. The three measures of contagion sensitivity were averaged to produce a single measure $(\alpha=$ $.59)$. We first examined the initial ratings of purchase intentions before any manipulation was described. As hypothesized, we observed a significant two-way interaction between celebrity valence (positive vs. negative) and contagion sensitivity $(\beta=.13, p<.01)$. For positive celebrities, there was a significant positive relationship between contagion sensitivity and purchase intentions $(\beta=.18, p<$ $.01)$. That is, participants who were more sensitive to contagion expressed greater purchase intentions for the positive celebrity objects. In contrast, for negative celebrities, contagion sensitivity was negatively related to purchase intentions $(\beta=-.12, p=.076)$, where participants who were more sensitive to contagion were less likely to purchase the negative celebrity objects.

We then examined whether contagion sensitivity moderated the effects of physical contact on purchase intentions. Indeed, for positive celebrities, participants' level of contagion sensitivity moderated the manipulation of contact on purchase intentions such that we observed a significant twoway interaction between the manipulation of physical contact and contagion sensitivity $(\beta=.18, p<.05)$. To explore the nature of the interaction, we compared whether there were significant differences across the contact conditions at both low and high levels of contagion sensitivity (see Aiken and West 1991; Fitzsimons 2008). Consistent with our hypotheses, the planned contrast for participants at high levels of contagion sensitivity $(+1 \mathrm{SD}$ from the mean) revealed a significant effect of contact on the change in willingness to purchase the item $(\beta=.53, p<.001)$. In contrast, for participants who were low in contagion sensitivity $(-1$ SD from the mean), the manipulation of contact had no effect on purchase intentions $(\beta=.15, p=.27)$. For negative celebrities, however, there was no interaction with contagion sensitivity $(\beta=-.01, p=.93)$, which is again consistent with the hypothesis that these objects are valued because of their perceived market value, not contagion. Given that the Cronbach's $\alpha$ for the measure of contagion sensitivity was not extremely high (because of a small number of items), we replicated the above patterns (i.e., higher contagion sensitivity positively correlated with willingness to purchase positive celebrity items and negatively correlated with willingness to purchase negative celebrity possessions) using each individual measure of contagion sensitivity as a moderating variable. The results of these analyses were identical to the patterns observed using the three-item scale.

Internal Replication. We replicated this pattern of results in a second experiment with a new sample of 310 adult participants. The design was nearly identical to the present study. However, for the manipulation of contagion, participants were told about a "sterilization" transformation that removed any evidence of the individual's contact with the item. Additionally, for the manipulation of market value, participants were told that they would be prohibited from reselling the items to others.

\section{Discussion}

For both positive and negative celebrity items, we observed that changes in market demand produced similar effects. Not surprisingly, highlighting demand increased purchase intentions while decreasing demand decreased purchase intentions. More important, however, the pattern was different for manipulations of physical contact. Here we observed the predicted interaction effect. For positive celebrities, highlighting contact increased purchase intentions, while for negative celebrities, highlighting contact decreased purchase intentions. The effects of physical contact (and their interaction with celebrity valence) suggest that contagion is indeed an important dimension influencing the valuation of celebrity items above and beyond any effects of market demands.

These results are also able to address an associative account. If the mere association between the celebrity and the object was the only factor driving valuation, then there should have been no effect of either the contact or market value transformations. Thus, the significant interaction between celebrity valence and manipulations of contact provides strong evidence against the associative explanation as well as an explanation based solely on market demands.

Additional support for contagion as a key underlying dimension came from the contagion sensitivity measures. Specifically, we observed that higher sensitivity to contagion was positively related to a desire to purchase objects owned by positive celebrities but negatively related to a desire to purchase objects owned by negative celebrities. Moreover, higher-contagion sensitivity individuals showed greater effects of physical contact on willingness to purchase a positive celebrity item. In our final study, we test the role of contagion more directly by experimentally manipulating participants' contagion beliefs.

\section{EXPERIMENT 3}

In a final study, we examined the effects of activating the concept of contagion via a subtle priming manipulation. Participants were exposed to either "contagious" or "not contagious" vignettes (see the appendix) and were then sub- 
sequently asked for their valuation of either positive or negative celebrity items. We predicted that activating the concept of contagion should make participants more sensitive to contagion and therefore (similar to contagion sensitivity) should interact with the valence of the celebrity, leading participants to value the negative celebrity items less and the positive celebrity items potentially more.

H3: There should be an interaction between the priming condition and celebrity valence. Priming contagion should lead participants to value the negative celebrity items less and the positive celebrity items more.

A second goal of this study was to explore scenarios in which the target individual was held constant rather than generated by participants. The method employed in the previous studies had the benefit of equating across a number of dimensions including participants' own familiarity with the celebrity, individual differences in categorization of the individual as positive or negative, and so forth. However, one question was whether the effects of the previous studies would be obtained if the target individuals were held constant. Therefore, participants were asked to evaluate objects that were said to have belonged to two positive individuals and two negative individuals, and we compared ratings of their possessions across the manipulations of celebrity valence (positive vs. negative) and priming condition (contagious vs. not contagious).

\section{Method}

We recruited a new group of 240 participants $\left(M_{\text {age }}=\right.$ $36.2,65 \%$ female) from the same online panel. Participants were randomly assigned to one of four between-subjects conditions in a 2 (valence: positive vs. negative) $\times 2$ (priming condition: contagious vs. not contagious) between-subjects design.

Participants were first primed by being asked to read the scenarios of high or low contagion. The prime consisted of four scenarios that included descriptions of an action either spreading to others or not spreading and remaining isolated. The actions consisted of a person laughing and other people in the vicinity also starting to laugh (or not), one person yawning and others also beginning to yawn (or not) (both of these were taken with permission directly from Mishra [2009]), the spread (or not) of the smell of a flower, and the spread (or not) of poison ivy among siblings. Therefore, the same action (e.g., laughing or yawning) was considered either contagious or not contagious, depending on whether it was spread or not. Since two of the vignettes used in this study were slightly different from the ones used by Mishra (2009), we conducted a pretest with a separate group of participants. Participants were first exposed to either the contagious or not contagious vignettes. Then, participants completed the three contagion sensitivity items used in experiment 2. As expected, participants expressed significantly greater sensitivity to contagion when exposed to the contagious $(M=5.79, \mathrm{SD}=1.88)$ versus not contagious vignettes $(M=5.17, \mathrm{SD}=2.05 ; t(182)=$ $2.11, p<.05)$.

Following the priming task, participants were asked to evaluate two celebrity objects (a sweater and a pair of sunglasses). Half of the participants evaluated objects that were said to belong to positive celebrities (Albert Einstein and Barack Obama) while the other half evaluated negative celebrity items (belonging to Charles Manson and Saddam Hussein). These names were taken from those generated by participants in experiments 1 and 2. As a manipulation check, participants were also asked to rate how much they liked the person $(1=$ extreme disliking, $9=$ extreme liking). As expected, participants reported liking Albert Einstein $(M=7.39)$ and Barack Obama $(M=6.74)$ significantly more than Charles Manson $(M=1.91)$ and Saddam Hussein $(M=1.84 ; F(1,237)=579.91, p<.001)$.

For each item, participants then responded to three questions that assessed their valuation of the item. These measures were the same as those used in experiment 1 (i.e., desire to own the item, willingness to purchase, willingness to keep the item vs. throw it out). These measures were highly correlated and were averaged to produce a single measure of valuation $(\alpha=.80)$. The order in which each item was presented was counterbalanced across participants and did not affect the results $(F<1)$. In this study, we did observe that, overall, men expressed greater valuation for the items than women $(\beta=.28, p<.001$, perhaps because all the targets were male) and that younger participants reported greater valuation than older ones $(\beta=-.18, p<$ $.01)$. The priming manipulation did not interact with these factors (all $p>.4$ ). However, for all subsequent analyses we included both participant gender and age as covariates.

\section{Results and Discussion}

Measures of valuation were submitted to a mixed-model ANCOVA with valence (positive vs. negative) and priming condition (contagious vs. not contagious) as between-subjects factors and the item (sweater vs. sunglasses) as a within-subjects factor. As predicted, this analysis revealed a significant two-way interaction between priming condition and celebrity valence $(F(1,233)=5.94, p<.05)$. For the negative celebrity items, participants who were exposed to the contagion prime rated the negative celebrity items as significantly less valuable $(M=2.10 ; \mathrm{SE}=.22)$ than participants who were exposed to the not contagious prime $(M=2.84 ; \mathrm{SE}=.22, F(1,116)=5.65, p<.05)$. Conversely, for positive celebrity items, participants who were exposed to the contagion prime rated the positive celebrity items as more valuable $(M=4.64$; $\mathrm{SE}=.24)$ than participants who were exposed to the not contagious prime $(M=$ 4.29; $\mathrm{SE}=.24)$. This difference, however, was not statistically significant ( $p=.31$ ). The priming manipulation had analogous effects on both targets and therefore did not interact with the particular positive or negative celebrity $(F<$ 1). Although the measures of liking were positively correlated with valuation $(p<.001)$, regression analyses indicated 
that this measure did not moderate the effect of the prime in either the positive $(p=.82)$ or the negative conditions $(p=.62)$.

The results from this study were consistent with the prediction that implicitly activating the concept of contagion would have different effects on the valuation of positive versus negative celebrity items. Specifically, activating the concept of contagion significantly reduced the degree to which participants valued the negative celebrity items. However, exposure to contagion had a different effect for positive celebrity items by increasing valuation (although this difference was not significant when compared to the not contagious prime).

The failure to find a significant increase in valuation for positive celebrities is potentially attributable to several different factors. Perhaps the most plausible explanation is that there is simply much less agreement in whom people identify as a positive celebrity. As noted earlier in experiment 2 , we observed much greater consensus about negative celebrities compared to positive ones. This difference could, in turn, explain the different effects of the contagion prime. Consistent with this interpretation, the variance in ratings of item value was greater in the positive celebrity conditions versus the negative celebrity conditions ( 3.55 vs. 3.29 , respectively).

\section{GENERAL DISCUSSION}

The primary goal of this article was to empirically test the degree to which contagion beliefs, in contrast to other motivations such as associations and market demands, account for the valuation of celebrity items. The present studies find that, indeed, contagion appears to play a central role in the valuation of celebrity possessions. Furthermore, we demonstrate the way in which contagion and market demands interact to influence purchase intentions. Specifically, experiment 1 demonstrated that, for positive celebrities, contagion and market demands seem to be complementary. Items belonging to positive celebrities appear to be valued both for their contact with an admired individual (contagion) and for their market value. In contrast, for negative celebrities, contagion and market demands appear to play contrasting roles in that perceived market demand increases the value of the object (relative to an item owned by a negative noncelebrity) whereas contagion decreases value.

Experiment 2 examined this interaction between contagion and valence in greater detail by directly manipulating the amount of contact that the individual had with the item. Supporting a contagion hypothesis, we observed that physical contact increased purchase intentions for positive celebrity items but decreased purchase intentions for negative celebrity items. This study also demonstrated that contagion sensitivity is an important moderator in the valuation of celebrity possessions. Individual differences in contagion sensitivity were positively related to a desire to purchase objects owned by positive celebrities but negatively related to a desire to purchase objects owned by negative celebrities. Finally, experiment 3 provided converging evidence for a contagion account by demonstrating that activating the concept of contagion via a priming manipulation changes people's willingness to purchase celebrity possessions.

Together, these results demonstrate that celebrity possessions are valued for reasons that go beyond mere associations or market demands. For instance, a merely associative account cannot explain the interaction between contagion and celebrity valence (experiment 2 ) nor the moderating role of contagion sensitivity (experiment 2), and an associative account makes no predictions regarding the effects of priming contagion (experiment 3 ). Moreover, the fact that some participants were willing to purchase negative celebrity objects, as revealed by the changes in purchase intentions in experiments 2 and 3, is inconsistent with a merely associative account given that the negative individuals were individuals whom participants said they explicitly detested. In other words, while some people in the real world may actually be admirers of Charles Manson or Saddam Hussein, this does not account for the participants in our studies who said they were willing to purchase these items after they had already identified the items' owners as someone whom they explicitly disliked. Consistent with this, explicit measures of liking did not predict willingness to purchase an object owned by a given celebrity.

\section{Limitations and Future Directions}

The present studies tended to examine extremes of positivity/negativity. In actuality, however, there may be many more cases of "mixed" valence. The results from experiment 1 suggest that as far as contagion effects are concerned, mixed-valence individuals tend to fall in the middle of extremely positive or extremely negative celebrities. Nevertheless, this may be an interesting avenue for future research given the number of ways in which valence may be "mixed." For example, what is the role of contagion for an individual such as Tiger Woods, who is highly regarded for his talent and sportsmanship as a golfer but received a great deal of backlash for his numerous affairs?

There may also be additional sources of value contributing to people's desire to purchase celebrity objects that we did not examine here. Indeed, the market value of celebrity items would seem to be representative of a much broader notion of value that may include a number of factors such as the item's value as a historical artifact, its age, or its status value to others. While the effects of contagion observed here suggest that these additional factors do not sufficiently account for people's willingness to purchase celebrity possessions, future research may look at these factors in greater detail.

There may also be important individual differences that interact with contagion beliefs. In the present studies, we observed some main effects of gender and age (e.g., in experiment 3). However, these factors did not interact with manipulations of contagion. Nevertheless, there may be situations in which the effects of contagion may be different for men and women (see Argo et al. 2008). Additionally, the desire for celebrity possessions may be related to traits that are quite stable across the lifetime, such as how sen- 
timental someone is or whether he/she possessed sentimental objects as a child (see Frazier et al. 2009).

Finally, these studies primarily examined the notion that contagion affects value via physical contact on both ends: for example, a celebrity touched an item and now you can also touch it. However, as Rozin and others have discussed (Argo et al. 2006, 2008; Morales and Fitzsimons 2007; Nemeroff and Rozin 1994; Rozin et al. 1986, 1989; Rozin and Nemeroff 2002), other modes of transmission might be available and equally effective. Indeed, Nemeroff and Rozin (1994) concluded that the mechanisms underlying the effects of "positive" versus "negative" physical contact are distinct. Specifically, the dislike and disgust for negative items appeared to derive from contagion beliefs, while interest and regard for positive items resulted from a symbolic interaction model that highlighted the moral and interpersonal factors that are communicated to the self and others through association with such positive items.

Here we find a direct effect of positive contagion on valuation. However, symbolic contagion would imply a "metaphysical" mode of transmission whereby some immaterial quality of a person (e.g., his/her moral status) is transferred to an object even without direct contact. For instance, it may be that items more closely associated with "core" features of a celebrity (e.g., Michael Jordan's shoes vs. Einstein's pen) will differentially have an impact on the effects of contagion. Therefore, future work may explore the interaction between physical modes of contagion versus more metaphysical/symbolic forms of contagion.

In sum, previous work on contagion has demonstrated that the belief in a transmission of essence is pervasive across cultures (Frazer 1890; Mauss 1902), may emerge early in development (Bloom 2004; Kalish 1996), and may have important effects on consumer behavior (Belk 1988; Mishra 2009; Morales and Fitzsimons 2007; O'Guinn 1991). To our knowledge, however, there has not been a previous attempt to directly examine the underlying reasons why people purchase celebrity possessions from the vantage of contagion effects. Therefore, the primary contribution of this article is to provide a clear empirical demonstration of the role of contagion in the valuation of celebrity possessions. Furthermore, these studies broaden the understanding of contagion as they illustrate how contagion may interact with competing market demands. Here we offer a new perspective on the phenomenon of contagion as these studies illustrate the ways in which contagion and market demands may either converge or diverge, depending on the valence of the individual who touched the object and the market demands surrounding that person.

\section{APPENDIX}

\section{CONTAGIOUS AND NOT CONTAGIOUS PRIMING MANIPULATIONS USED IN EXPERIMENT 3}

The first two scenarios in each section were taken from Mishra (2009).

\section{CONTAGIOUS VIGNETTES}

Tom saw some students standing in front of a bulletin board. He was interested and went to see what they were all looking at. He saw that some cartoons had been posted. He found the cartoons very funny and started laughing very hard. Looking at him laugh, others also joined in, and soon the entire group of people were laughing.

John, a fifth grader, was sitting in his class in the afternoon. He was feeling a little sleepy and he yawned. He looked around and saw that Rita, who was sitting next to him, also started yawning. He then noticed that five other students also were yawning. His yawn had caused the other students to start yawning.

Jennifer was on vacation with her family in Hawaii. On the vacation, Jennifer's family went to a flower garden, and as a souvenir Jennifer got to take home a beautiful flower. The flower smelled very good, and the smell was very strong. For the rest of the trip, Jennifer carried the flower around in her bag with the rest of her clothes. By the end of the trip, the smell of the flower had spread to all of her other things. Even when she took her clothes out of the bag, they still smelled like the flower.

Alex has many brothers and sisters. One day, Alex was playing in the woods behind his house and he brushed his leg on some poison ivy. Alex did not realize that he had touched the ivy, and he began scratching the poison ivy and spreading it on his hands and arms. Later that day, Alex was playing with his brothers and sisters and he spread the poison ivy to his siblings. Nobody was injured, but by the end of the day the poison ivy had spread to all of the children and they were all very itchy.

\section{NOT CONTAGIOUS}

Tom saw some students standing in front of a bulletin board. He was interested and went to see what they were all looking at. He saw that some cartoons had been posted. He found the cartoons very funny and started laughing. Other children looked at him but did not laugh, and Tom saw that he was the only person laughing. He went away laughing and thinking about the cartoons.

John, a fifth grader, was sitting in his class in the afternoon. He was feeling a little sleepy and he yawned. He looked around and saw that Rita, who was sitting next to him, was not yawning. He looked around and found that no other student was yawning. His yawn had not caused any of the other students to yawn.

Jennifer was on vacation with her family in Hawaii. On the vacation, Jennifer's family went to a flower garden, and as a souvenir Jennifer got to take home a beautiful flower. The flower smelled very good, and the smell was very strong. For the rest of the trip, Jennifer carried the flower in a special zip lock bag. By the end of the trip, however, the smell of the flower had gone away. The flower no longer smelled, so Jennifer decided to leave it behind.

Alex has many brothers and sisters. One day, Alex was playing in the woods behind his house and he brushed his 
leg on some poison ivy. Alex realized that he had touched the ivy, and so he was careful to not scratch the poison ivy or spread it to his hands and arms. Later that day, Alex was playing with his brothers and sisters, but first his mom had treated the poison ivy with lotion and covered it up. By the end of the day the poison ivy was almost gone and Alex's leg no longer itched.

\section{REFERENCES}

Aiken, Leona and Stephen G. West (1991), Multiple Regression: Testing and Interpreting Interactions, Newbury Park, CA: Sage.

$\rightarrow$ Argo, Jennifer J., Darren W. Dahl, and Andrea C. Morales (2006), "Consumer Contamination: How Consumers React to Products Touched by Others," Journal of Marketing, 70 (April), 81-94.

$\rightarrow$ - (2008), "Positive Consumer Contagion: Responses to Attractive Others in Retail Contexts," Journal of Marketing Research, 45 (December), 690-701.

$\rightarrow$ Belk, Russell W. (1988), "Possessions and the Extended Self," Journal of Consumer Research, 15 (September), 139-67.

__ (1995), Collecting in a Consumer Society, New York: Routledge.

Bloom, Paul (2004), Descartes' Baby: How the Science of Child Development Explains What Makes Us Human, New York: Basic Books.

- (2010), How Pleasure Works: The New Science of Why We Like What We Like, New York: Norton.

$\rightarrow$ Burton, Benjamin J. and Joyce P. Jacobsen (1999), "Measuring Returns on Investments in Collectibles," Journal of Economic Perspectives, 13 (Autumn), 193-212.

Cornfeld, Betty and Owen Edwards (1983), Quintessence: The Quality of Having It, New York: Crown.

Douglas, Mary and Baron Isherwood (1979), The World of Goods, New York: Basic Books.

$\rightarrow$ Fitzsimons, Gavan J. (2008), "Death to Dichotomizing," Journal of Consumer Research, 35 (June), 5-8.

Formanek, Ruth (1991), "Why They Collect: Collectors Reveal Their Motivations," Journal of Social Behavior and Personality, 6 (Special Issue), 275-86.

Frazer, James George (1890/1959), The New Golden Bough: A Study in Magic and Religion, abridged, ed. T. H. Gaster, New York: Macmillan.

$\rightarrow$ Frazier, Brandy N., Susan A. Gelman, Alice Wilson, and Bruce Hood (2009), "Picasso Paintings, Moon Rocks, and HandWritten Beatles Lyrics: Adults' Evaluations of Authentic Objects," Journal of Cognition and Culture, 9 (1-2), 1-14.

$\rightarrow$ Garber, Peter M. (1989), “Tulipmania,” Journal of Political Economy, 97 (June), 535-57.

- (2000), Famous First Bubbles: The Fundamentals of Early Manias, Cambridge, MA: MIT Press.

$\rightarrow$ Grayson, Kent and David Shulman (2000), "Indexicality and the Verification Function of Irreplaceable Possessions: A Semiotic Analysis," Journal of Consumer Research, 27 (June), 17-30.

$\rightarrow$ Haidt, Jonathan, Clark McCauley, and Paul Rozin (1994), "Individual Differences in Sensitivity to Disgust: A Scale Sampling Seven Domains of Disgust Elicitors," Personality and Individual Differences, 16 (May), 701-13.

$\rightarrow$ Kalish, Charles W. (1996), "Preschoolers' Understanding of Germs as Invisible Mechanisms," Cognitive Development, 11 (1), 83-106.
Mackay, Charles (1841/1932), Extraordinary Popular Delusions and the Madness of Crowds, reprint, New York: Noonday.

Mauss, Marcel (1902/1972), A General Theory of Magic, trans. R. Brain, New York: Norton.

$\rightarrow$ McCracken, Grant (1986), "Culture and Consumption: A Theoretical Account of the Structure and Movement of the Cultural Meaning of Consumer Goods," Journal of Consumer Research, 13 (June), 71-84.

$\rightarrow$ — (1989), "Who Is the Celebrity Endorser? Cultural Foundations of the Endorsement Process," Journal of Consumer Research, 16 (December), 310-21.

$\rightarrow$ Mishra, Arul (2009), "Influence of Contagious versus Noncontagious Product Groupings on Consumer Preferences," Journal of Consumer Research, 36 (June), 73-82.

$\rightarrow$ Morales, Andrea C. and Gavan Fitzsimons (2007), "Product Contagion: Changing Consumer Evaluations through Physical Contact with 'Disgusting' Products," Journal of Marketing Research, 44 (May), 272-83.

Nemeroff, Carol J. and Paul Rozin (1994), "The Contagion Concept in Adult Thinking in the United States: Transmission of Germs and of Interpersonal Influence," Ethos: Journal of the Society for Psychological Anthropology, 22 (June), 158-86.

O'Guinn, Thomas C. (1991) "Touching Greatness: The Central Midwest Barry Manilow Fan Club," in Highways and Buyways: Naturalistic Research from the Consumer Behavior Odyssey, ed. Russell W. Belk, Provo, UT: Association for Consumer Research, 102-11.

$\rightarrow$ O'Guinn, Thomas C. and Russell W. Belk (1989), "Heaven on Earth: Consumption at Heritage Village, USA," Journal of Consumer Research, 15 (September), 227-38.

$\rightarrow$ Preacher, Kristopher J. and Andrew F. Hayes (2008), “Asymptotic and Resampling Procedures for Assessing and Comparing Indirect Effects in Multiple Mediator Models," Behavior Research Methods, 40 (3), 879-91.

$\rightarrow$ Rozin, Paul, April Fallon, and Robin Mandell (1984), "Family Resemblance in Attitudes to Foods," Developmental Psychology, 20 (March), 309-14.

Rozin, Paul, Linda Millman, and Carol J. Nemeroff (1986), “Operation of the Laws of Sympathetic Magic in Disgust and Other Domains," Journal of Personality and Social Psychology, 50 (April), 703-12.

Rozin, Paul and Carol J. Nemeroff (2002), "Sympathetic Magical Thinking: The Contagion and Similarity 'Heuristics," in $\mathrm{Heu}$ ristics and Biases: The Psychology of Intuitive Judgment, ed. Thomas Gilovich, Dale Griffin, and Daniel Kahneman, Cambridge: Cambridge University Press, 201-16.

Rozin, Paul, Carol J. Nemeroff, Marcia Wane, and Amy Sherrod (1989), "Operation of the Sympathetic Magical Law of Contagion in Interpersonal Attitudes among Americans," Bulletin of the Psychonomic Society, 27 (4), 367-70.

$\rightarrow$ Shrout, Patrick E. and Niall Bolger (2002), "Mediation in Experimental and Nonexperimental Studies: New Procedures and Recommendations," Psychological Methods, 7 (December), 422-45.

Stone, Gigi (2007). “'Murderabilia' Sales Distress Victims’ Families," ABC News Online, April 15, http://abcnews.go.com/ WNT/US/Story $? \mathrm{id}=2999398 \&$ page $=1$.

$\rightarrow$ Thompson, Earl A. (2007), "The Tulipmania: Fact or Artifact?" Public Choice, 130 (1-2), 99-114.

Tylor, Edward Burnett (1871/1974), Primitive Culture: Researches into the Development of Mythology, Philosophy, Religion, Art, and Custom, New York: Gordon. 
$\rightarrow$ Zauberman, Gal, Rebecca K. Ratner, and B. Kyu Kim (2009), "Memories as Assets: Strategic Memory Protection in Choice over Time," Journal of Consumer Research, 35 (February), 715-28. $\rightarrow$ Zhao, Xinshu, John G. Lynch Jr., and Qimei Chen (2010), "Reconsidering Baron and Kenny: Myths and Truths about Mediation Analysis," Journal of Consumer Research, 37 (August), 197-206. 
$\rightarrow$ Zauberman, Gal, Rebecca K. Ratner, and B. Kyu Kim (2009), "Memories as Assets: Strategic Memory Protection in Choice over Time," Journal of Consumer Research, 35 (February), 715-28. $\rightarrow$ Zhao, Xinshu, John G. Lynch Jr., and Qimei Chen (2010), "Reconsidering Baron and Kenny: Myths and Truths about Mediation Analysis," Journal of Consumer Research, 37 (August), 197-206. 